Article

\title{
Estimating Tropical Cyclone Intensity in the South China Sea Using the XGBoost Model and FengYun Satellite Images
}

\author{
Qingwen Jin ${ }^{1,2}$, Xiangtao Fan ${ }^{1,3}$, Jian Liu ${ }^{1,3, *}$, Zhuxin Xue ${ }^{4} \mathbb{C}$ and Hongdeng Jian ${ }^{1}$ \\ 1 Key Laboratory of Digital Earth Science, Aerospace Information Research Institute, Chinese Academy of \\ Sciences, Beijing 100094, China; jinqw@radi.ac.cn (Q.J.); fanxt@radi.ac.cn (X.F.); jianhd@radi.ac.cn (H.J.) \\ 2 University of Chinese Academy of Sciences, Beijing 100049, China \\ 3 Hainan Key Laboratory of Earth Observation, Sanya 572029, China \\ 4 Beijing Jinghang Computation and Communication Research Institute, Beijing 100074, China; \\ xuezx@radi.ac.cn \\ * Correspondence: liujian@radi.ac.cn
}

Received: 20 March 2020; Accepted: 20 April 2020; Published: 22 April 2020

\begin{abstract}
Conventional numerical methods have made significant advances in forecasting tropical cyclone (TC) tracks, using remote sensing data with high spatial and temporal resolutions. However, over the past two decades, no significant improvements have been made with regard to the accuracy of TC intensity prediction, which remains challenging, as the internal convection and formation mechanisms of such storms are not fully understood. This study investigated the relationship between remote sensing data and TC intensity to improve the accuracy of TC intensity prediction. An intensity forecast model for the South China Sea was built using the eXtreme Gradient Boosting (XGBoost) model and FengYun-2 (FY-2) satellite data, environmental data, and best track datasets from 2006 to 2017. First, correlation analysis algorithms were used to extract the TC regions in which the satellite data were best correlated, with TC intensity at lead times of $6,12,18$, and $24 \mathrm{~h}$. Then, satellite, best track, and environmental data were used as source data to develop three different XGBoost models for predicting TC intensity: model A1 (climatology and persistence predictors + environmental predictors), model A2 (A1 + satellite-based predictors extracted as mean values), and model A3 (A1 + satellite-based predictors extracted by our method). Finally, we analyzed the impact of the FY-2 satellite data on the accuracy of TC intensity prediction using the forecast skill parameter. The results revealed that the equivalent blackbody temperature (TBB) of the FY-2 data has a strong correlation with TC intensity at $6,12,18$, and $24 \mathrm{~h}$ lead times. The mean absolute error (MAE) of model A3 was reduced by $0.47 \%, 1.79 \%, 1.91 \%$, and $5.04 \%$ in $6,12,18$, and $24 \mathrm{~h}$ forecasts, respectively, relative to those of model A2, respectively, and by $2.73 \%, 7.58 \%, 7.64 \%$, and $5.04 \%$ in $6,12,18$, and $24 \mathrm{~h}$ forecasts, respectively, relative to those of model A1. Furthermore, the accuracy of TC intensity prediction is improved by FY-2 satellite images, and our extraction method was found to significantly improve upon the traditional extraction method.
\end{abstract}

Keywords: satellite data; South China Sea; tropical cyclone intensity; XGBoost

\section{Introduction}

Over the past 20 years, the use of numerical weather prediction models has improved the forecast accuracy of tropical cyclone (TC) track by about $50 \%$ for lead times of $24-72 \mathrm{~h} \mathrm{[1]}$. One of the main reasons for this improved accuracy is the use of high resolution remote sensing data. Satellite data are very important in the accurate tracking of fast-moving TCs, because they contain effective observational information for optimizing the initial numerical prediction field. Furthermore, 
high-spatiotemporal-resolution satellite measurements can provide observational data for areas lacking ground observational data [2]. For example, cloud data from satellite images have been employed to improve the accuracy of numerical prediction [3], and wind information contained in satellite data has been employed to improve TC forecast accuracy [4]. Despite the advancements in the use of numerical models, the past two decades have seen little improvement in the accuracy of TC intensity prediction for lead times of 24-72 h [5], and although meaningful improvements have been seen in TC intensity forecasting, such forecasting remains challenging, as the internal convection and formation mechanisms of such storms are not fully understood [6].

In addition to conventional numerical methods, the statistical-dynamical approach has been used as an operational guide for TC intensity prediction. The "statistical hurricane prediction scheme" (SHIPS) has used this approach successfully in the North Atlantic and East Pacific to predict TC intensity [7]. The first version of the "statistical typhoon intensity forecasting scheme" (STIPS) was developed by Knaff et al. [8] in 2002, to predict TC intensity based on the SHIPS. In 2003, the STIPS was improved and applied in operational settings. Following this, Gao and Chiu [9] attempted to predict TC intensity using an artificial neural network-based method; they proved that the accuracy of a scheme using neural network models was superior to that of one using multiple linear regression models, leading to the recent adoption of this method to predict TC intensity. In another study, in which the intensity of TCs was forecast using a radial-basis function network (RBFN), multilayer perceptron (MLP) model, and statistical multiple linear and ordinary linear regression [10], the MLP model was found to have the lowest forecasting error. Chandra and Dayal [11], predicted cyclone wind intensity in the South Pacific region using Elman recurrent neural networks, and Chaudhuri et al. [12] found a double hidden layer neural network to be more accurate than a single-layer network for forecasting typhoon intensity. Thus, as described above, most researchers use a non-linear model to predict TC intensity.

Given the advancements in satellite data, some researchers investigated the use of satellite data in TC intensity forecasting [13]. TC intensity in the North Indian Ocean was predicted by incorporating average values from satellite data into a set of predictors, and it was found that the addition of satellite data improved the prediction model [11]. Gao et al. predicted TC intensity using a decision tree and satellite data; they showed that employing the ocean coupling potential intensity index with satellite data reduced the accuracy of the TC intensity prediction [13]. The satellite predictors were extracted as area-averaged data, extracting detailed information using the mean results in the details being hidden or diluted. The satellite data are particularly rich around the center of the TC, and this data can describe the convective characteristics affecting TC intensity [14]. Wang [15] suggested that convection near the TC center is a key feature of overall convection in tropical cyclogenesis and that the spatial pattern of the convection intensity might also be important. Given such findings, a new extraction method that can comprehensively glean TC intensity information from remote sensing data could improve TC intensity prediction [16].

In recent years, some scholars have shown that the decision tree method can improve the accuracy of the TC intensity prediction. TC intensity in the western North Pacific was predicted using the decision tree method [17]. The theory and application of the decision tree method have developed significantly since Chen's proposal of the eXtreme Gradient Boosting (XGBoost) model [18]; this model has been applied in several studies, on topics including image classification [19], speech recognition [20], and biomedical studies [21]. The XGBoost model has also proved to be useful in predicting TC intensity [22]. TC intensity is affected by several factors that are often ambiguous and uncertain. In this study, we used the XGBoost model to predict TC intensity, because its algorithm can handle many dimensions and be used to conduct multi-factor predictions. Factor mining has proved to be useful in forecasting model constructions [23,24]. The XGBoost model can also be used in conjunction with factor mining, which has proved to be useful in forecasting model construction. Furthermore, another advantage of the XGBoost model is its very low computational cost for users with a basic knowledge of TCs. 
Therefore, we focused on using satellite predictors extracted via a new method, to establish a machine learning model for predicting TC intensity. This study aimed to establish an XGBoost-based framework to predict TC intensity in the South China Sea, using data from the China Meteorological Administration-Shanghai Typhoon Institute (CMA-STI) [25], meteorological variables from the European Centre for Medium-Range Weather Forecasts (ECMWF) [26], and satellite data from the National Satellite Meteorological Center FengYun Satellite Data Center, covering the period of 2006-2017. The differences between the predicted and observed data were used to analyze the dynamics of TC intensity development. The primary objectives of this study were: (1) to establish a South China Sea TC intensity prediction model based on the XGBoost framework and satellite-based potential predictors; (2) to analyze the influence of the FengYun-2 (FY-2) remote sensor data on TC intensity forecast results, and (3) to analyze the influence of the satellite data extraction method used on TC intensity forecast results.

\section{Materials and Methods}

We considered three types of potential predictors-satellite, best track, and environmental data-to establish a South China Sea TC intensity model, based on the framework shown in Figure 1. We prepared all the data and the theoretical basis for our models as described in Sections 2.1 and 2.2. The formulation of the TC intensity prediction model is presented in Section 2.3.

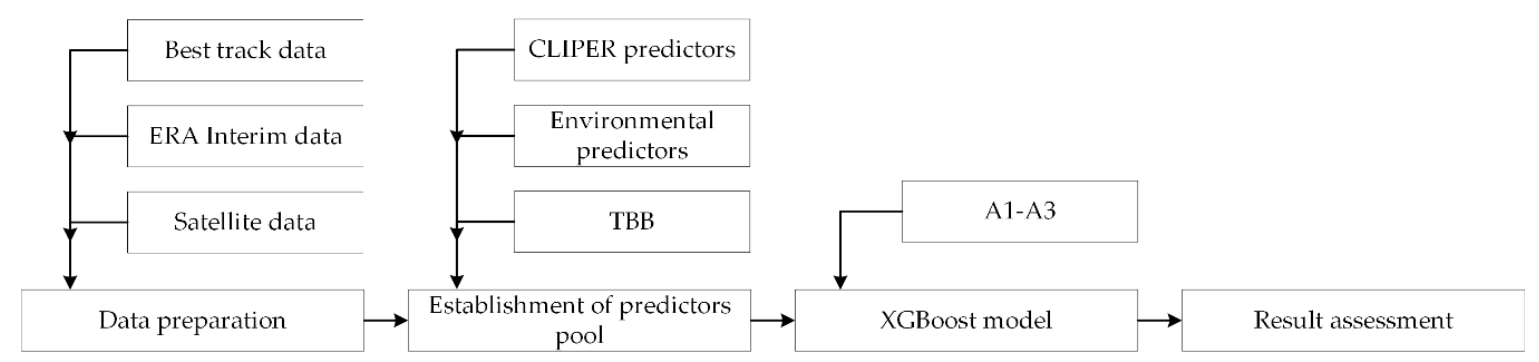

Figure 1. Flowchart of proposed TC intensity prediction model.

\subsection{Data}

The South China Sea was chosen as the study area for three reasons. Firstly, TCs in the South China Sea include those generated locally and those that travel into the South China Sea from the western North Pacific Ocean [27]. Secondly, the accuracy of South China Sea TC track predictions in 2018 was significantly higher than that in 2017, but the accuracy of TC intensity predictions did not significantly improve in this time period [28]. Finally, several TCs with concentrated landing times have affected coastal areas of the South China Sea, and such storms may induce serious secondary disasters [29].

The datasets used in this study, including their spatial and temporal resolutions and temporal coverage, are described in Table 1. Owing to the limitations of satellite data transmission time, the data used in this study relating to TCs and their surrounding environments in the South China Sea were limited to the period of 2006-2017. To ensure a well-constructed model, the ratio of training samples to experimental samples was approximately 7:3. TC data from 2006 to 2012 were selected for use as training samples and data from 2013 to 2017 were selected as the experimental samples. All TCs considered had been generated in or had entered the study area $\left(105^{\circ} \mathrm{E}\right.$ to $120^{\circ} \mathrm{E}, 10^{\circ} \mathrm{N}$ to $\left.25^{\circ} \mathrm{N}\right)$ and had a minimum lifetime of 48 hours. The number of samples selected for each lead time is listed in Table 2. 
Table 1. Dataset characteristics.

\begin{tabular}{cccccc}
\hline \multicolumn{2}{c}{ Dataset } & $\begin{array}{c}\text { Spatial } \\
\text { Resolution }\end{array}$ & $\begin{array}{c}\text { Temporal } \\
\text { Resolution }\end{array}$ & Spatial Coverage & $\begin{array}{c}\text { Temporal } \\
\text { Coverage }\end{array}$ \\
\hline \multicolumn{2}{c}{ CMA-STI } & $0.1^{\circ}$ & $6 \mathrm{~h}$ & Northwest Pacific & $1949-2017$ \\
\multicolumn{2}{c}{ ERA Interim } & $1^{\circ} \times 1^{\circ}$ & $6 \mathrm{~h}$ & Global & $1979-2017$ \\
\multirow{2}{*}{ TBB } & FY-2C & $0.05^{\circ} \times 0.05^{\circ}$ & $1 \mathrm{~h}$ & Global & $2006-2009$ \\
& FY-2E & $0.05^{\circ} \times 0.05^{\circ}$ & $1 \mathrm{~h}$ & Global & $2010-2017$ \\
& FY-2G & $0.05^{\circ} \times 0.05^{\circ}$ & $1 \mathrm{~h}$ & Global & $2015-2017$ \\
\hline \multicolumn{5}{c}{ Note $\mathrm{TBB}=$ blackbody temperature. }
\end{tabular}

Note: TBB = blackbody temperature.

Table 2. Number of TC training and test samples used for 6, 12, 18, and $24 \mathrm{~h}$ lead-time assessments.

\begin{tabular}{cccc}
\hline Lead Time (h) & All Samples (2006-2017) & $\begin{array}{c}\text { Training Samples } \\
\mathbf{( 2 0 0 6 - 2 0 1 2 )}\end{array}$ & $\begin{array}{c}\text { Test Samples } \\
\mathbf{( 2 0 1 3 - 2 0 1 7 )}\end{array}$ \\
\hline 6 & 1164 & 770 & 394 \\
12 & 1041 & 697 & 344 \\
18 & 922 & 625 & 297 \\
24 & 808 & 557 & 251 \\
\hline
\end{tabular}

The CMA-STI best track dataset includes the TC position (latitude and longitude), TC intensity category, minimum pressure near the TC center, and 2 min mean maximum sustained wind near the TC center. The 2006-2017 South China Sea TC datasets were downloaded from the CMA-STI best track dataset covering the western North Pacific (http://www.typhoon.gov.cn/) [25].

The environmental datasets were drawn from the ECMWF Re-Analysis (ERA-Interim) dataset [30]. This dataset provides assimilation analysis data four times daily at 00:00, 06:00, 12:00, and 18:00. Its spatial resolution is $1^{\circ} \times 1^{\circ}$. We selected environmental variables including relative humidity, temperature, divergence, and $\mathrm{u}$ - and v-wind at 200, 250, 300, 350, 400, 450, 500, 700, 750, 775, 800, 825, and $850 \mathrm{hPa}$. The maximum potential intensity (MPI) was estimated using sea surface temperature from the ERA-Interim dataset and CMA-STI best track dataset.

Remote sensing satellite data can provide high-precision meteorological information for TC intensity prediction [2]. In this study, satellite datasets were used to identify a convective intensity feature. The visible and infrared spin scan-radiometer sensor used on the CMA's FY satellites is a scanning instrument that provides measurements of oceanic and atmospheric parameters relevant to regional water and energy cycles [31-33]. As different FY-series satellites operated during 2006-2017, data from the FY-2C, FY-2E, and FY-2G sensors were selected to cover the entire study period. The FY-2C satellite instrument was launched on October 19, 2004 and ceased operations on December 28, 2009, and the temporal coverage of the available data extended from May 2005 to January 2010. The FY-2E satellite instrument was launched on June 15, 2008 and ceased operations on June 2, 2015; the temporal coverage of the available data was from December 2009 to January 2019. The FY-2G satellite instrument was launched on June 3, 2015, and the temporal coverage of its available data extends from June 2015 to present. The FY-2 data obtained for this study were downloaded from the National Satellite Meteorological Center FengYun Satellite Data Center (http://satellite.nsmc.org.cn/PortalSite/Data/Satellite.aspx) [34]. The selected satellite product was the blackbody temperature (TBB), which represents the most primitive observational data for cloud formation and display enhancement.

\subsection{Methods}

\subsubsection{XGBoost Theoretical Framework}

The XGBoost model is a heavy end-to-end promoting tree system, that is improved based on a gradient-boosting decision tree algorithm [18]. XGBoost is an ensemble method that can integrate 
several weak learners into a powerful learner for prediction. XGBoost aims to prevent overfitting and decrease the cost of computing resources, by reducing the objective function using regularization terms. The prediction process using the XGBoost model is presented in Figure 2.

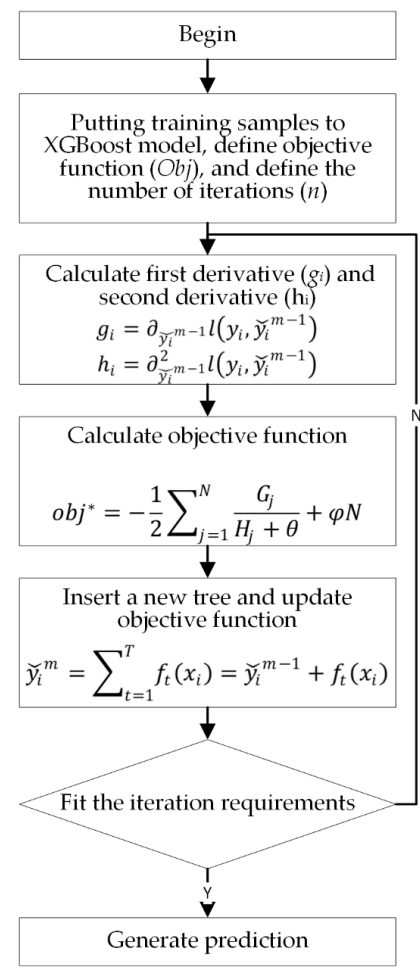

Figure 2. Principles of the XGBoost algorithm used as a predictive model.

The XGBoost model generates a strong ensemble regression tree, through the combination of several weak regression trees. Firstly, according to the principles and requirements of the XGBoost model, we organized the training sample set, defined the objective function $(O b j)$, and selected a number of iterations (n) for model training. Secondly, the first derivative $g_{i}=\partial_{\check{y}_{i}{ }^{m-1}} l\left(y_{i}, \check{y}_{i}{ }^{m-1}\right)$ and second derivative $h_{i}=\partial_{\breve{y}_{i}{ }^{m-1}}^{2} l\left(y_{i}, \breve{y}_{i}{ }^{m-1}\right)$ (calculated before the training) were summed, generating $\left(G_{j}\right.$ and $H_{j}$ ). Thirdly, to prevent overfitting, we employed regularization and obtained a new objective function $o b j^{*}=-\frac{1}{2} \sum_{j=1}^{N} \frac{G_{j}}{H_{j}+\theta}+\varphi N$. Fourth, we added a new tree to the original tree $\check{y}_{i}{ }^{m}=\sum_{t=1}^{T} f_{t}\left(x_{i}\right)=\check{y}_{i}{ }^{m-1}+f_{t}\left(x_{i}\right)$. After many iterations, the model's ensemble regression trees were formed.

\subsubsection{Embedded Selection Algorithm}

Among the many predictors, predictor information is sometimes duplicated, and some predictors were not related to TC intensity. As inputting irrelevant predictors or predictors with repetitive information into the model reduces the model's generalization ability, the embedded selection algorithm was used to select satellite predictors and remove irrelevant and duplicate predictors. Feature selection is automatically performed during the learning process of the algorithm, which can compensate for the shortcomings of the encapsulated and filtered feature selection algorithms. We used the learning model (XGBoost) to select the most valuable predictors for subsequent model design. 


\subsection{Formulation of the TC Intensity Prediction Model}

A model for predicting the TC intensity in the South China Sea was established by applying XGBoost to FengYun satellite images. The predictor extraction and parameter adjustment methods employed in the TC intensity prediction model are discussed in Sections 2.3.1 and 2.3.2, respectively, and our experimental design is presented in Section 2.3.3.

\subsubsection{Predictor Extraction Method}

This study aimed to develop a machine learning model for predicting TC intensity in the South China Sea, at lead times of 6, 12, 18, and $24 \mathrm{~h}$. Climatology and persistence (CLIPER), environmental, and satellite-based predictors were used as input variables for the XGBoost model, and the output variable was TC intensity change.

\section{Climatology and Persistence (CLIPER) Factors}

Both linear and non-linear models have been built using CLIPER predictors to simulate TC intensity changes $[35,36]$. The CLIPER parameters values are computed in terms of TC location, pressure, and time of the year. To select relevant climatology and persistence factors, motion features and climatology and persistence factors at the initial time and during the previous period are described. The climatology and persistence variables used in this study were the same as those used by Baik [36] and Zhu [37], and because the month of occurrence of the TC and the intensity category of the TC affect the TC intensity, we added month and intensity categories based on the predictors proposed by Zhu [37]. The CLIPER predictors used in this study are given in Table 3. Following this preliminary selection, a set of potential CLIPER predictors for TC intensity at each lead time $(6,12,18$, and $24 \mathrm{~h})$ was chosen. To fully show the effects of the CLIPER predictors, we established square terms based on the existing CLIPER factors. In addition to the predictors in Table 3, other potential predictors are described in Jin [22].

Table 3. Climatology and persistence, environmental, and satellite-based predictors used in this study.

\begin{tabular}{|c|c|}
\hline Predictors & Description \\
\hline \multicolumn{2}{|c|}{ Climatology and Persistence } \\
\hline Latitude & Latitude $0,6,12,18$, and $24 \mathrm{~h}$ ahead \\
\hline Longitude & Longitude $0,6,12,18$, and $24 \mathrm{~h}$ ahead \\
\hline $\begin{array}{c}\text { Minimum pressure near the tropical cyclone (TC) } \\
\text { center }\end{array}$ & $\begin{array}{c}\text { Minimum pressure near the TC center } 0,6,12,18 \text {, and } 24 \mathrm{~h} \\
\text { ahead }\end{array}$ \\
\hline $\begin{array}{c}2 \text { min mean maximum sustained wind near the TC } \\
\text { center }\end{array}$ & $\begin{array}{l}2 \text { min mean maximum sustained wind near the TC center } 0,6 \text {, } \\
\qquad 12,18 \text {, and } 24 \mathrm{~h} \text { ahead }\end{array}$ \\
\hline Month & Month of TC $0,6,12,18$, and $24 \mathrm{~h}$ ahead \\
\hline Intensity category & TC intensity category $0,6,12,18$, and $24 \mathrm{~h}$ ahead \\
\hline \multicolumn{2}{|c|}{ Environmental Factors } \\
\hline MPI & Maximum potential intensity based on equation (1) below \\
\hline RHLO & Area-averaged $(200-800 \mathrm{~km})$ relative humidity at $700-850 \mathrm{hPa}$ \\
\hline RHHI & Area-averaged $(200-800 \mathrm{~km})$ relative humidity at $300-500 \mathrm{hPa}$ \\
\hline U200 & Area-averaged $(200-800 \mathrm{~km})$ zonal wind at $200 \mathrm{hPa}$ \\
\hline T200 & Area-averaged $(0-1000 \mathrm{~km})$ temperature at $200 \mathrm{hPa}$ \\
\hline D200 & Area-averaged (200-800 km) divergence at $200 \mathrm{hPa}$ \\
\hline SHRS & Area-averaged $(200-800 \mathrm{~km}) 500-850 \mathrm{hPa}$ wind shear \\
\hline SHRD & Area-averaged (200-800 km) 200-850 hPa wind shear \\
\hline USHRS & Area-averaged (200-800 km) 500-850 hPa zonal wind shear \\
\hline USHRD & Area-averaged (200-800 km) 200-850 hPa zonal wind shear \\
\hline Vr850 & Area-averaged $(0-1000 \mathrm{~km}) 850 \mathrm{hPa}$ relative vorticity \\
\hline \multicolumn{2}{|c|}{ Satellite-based Factors } \\
\hline TBB & Equivalent blackbody temperature \\
\hline
\end{tabular}




\section{Environmental Factors}

Table 3 also presents the environmental variables used in the study. Environmental factors were obtained according to the "perfect prog" theory $[8,38]$. Perfect prog is an ideal application environment, which generally uses a multiple linear regression model to process the output of a numerical model, which in this case is the predictors. In the experimental stage, we use reanalysis data to replace the output of the numerical model. The environmental factors selected in this study were divided into three categories, including factors related to sea surface temperature, moisture fields, and wind fields. The values for the first category were drawn from the ERA-Interim dataset and were interpolated into the TC center, and those for the latter two categories were averaged around the center.

Sea surface temperature (SST) primarily serves to estimate the upper bound of TC intensity. The best indicator to describe the upper bound of TC intensity is MPI. MPI values can be calculated theoretically [39-41] or empirically [8,39,42]. The empirical method was selected based on the approach of DeMaria and Kaplan [39]. The SST selected from the ERA-Interim dataset was interpolated to the TC center according to the best track data from 2006-2017, to determine the relationship between SST and TC intensity [9], as follows:

$$
\mathrm{MPI}=\mathrm{A}+\mathrm{B} e^{\mathrm{C}\left(T-T_{0}\right)}
$$

The values were set as follows: $\mathrm{A}=17.76 \mathrm{~m} / \mathrm{s}, \mathrm{B}=49.69 \mathrm{~m} / \mathrm{s}, \mathrm{C}=0.1218^{\circ} \mathrm{C}^{-1}$, and $T_{0}=30.0^{\circ} \mathrm{C}$. The maximum value of MPI was $75 \mathrm{~m} / \mathrm{s}$. The CMA-STI best track dataset and 2 min sustained maximum wind speed were used to compute the correlation coefficient in our study, whereas Knaff used the JTWC best track dataset and 1 min sustained maximum wind speed to estimate the coefficient.

Because convection is the direct power source for a TC, variations in relative humidity can affect the TC intensity [9]. The average relative humidity at 700, 750, 800, and $850 \mathrm{hPa}$ (RHLO); average relative humidity at 300, 400, 450, and $500 \mathrm{hPa}$ (RHHI); zonal wind at $200 \mathrm{hPa}$ (U200); temperature at $200 \mathrm{hPa}$ (T200); divergence at $200 \mathrm{hPa}$ (D200); relative vorticity at $850 \mathrm{hPa}$ (Vr850); average zonal wind shear at 500, 700, 750, 800, and $850 \mathrm{hPa}$ (USHRS); and average wind shear at 200, 250, 300, 400, 450, 500, $700,750,800$, and $850 \mathrm{hPa}$ (USHRD) were chosen as the environmental predictors to assess the potential impact of moisture and wind fields on TC intensity. As vertical wind shear has also been found to be crucial in predicting TC intensity $[9,36,43]$, we considered two additional factors, defined as the difference between the 850 and $200 \mathrm{hPa}$ horizontal wind vectors (SHRS) and the difference between the 850 and $500 \mathrm{hPa}$ horizontal wind vectors (SHRD). We applied an environmental factor extraction method, based on the approach of Gao and Knaff $[8,9,44]$. To fully show the effects of environmental factors, we established some square and cubic terms based on the existing factors [8,9]. In addition to the predictors in Table 3, other potential predictors are described in Jin [22].

\section{Satellite-Based Factors}

The relationship between TBB and TC intensity has previously been quantified [45-47]. Weatherford and Gray [48] showed that TCs have fast outer-core winds that restrict inflow to the eye-wall; based on their results, Mundell [49] noted that a high ratio of inner-to outer-core convection indicates future intensification, as this suggest that the inner-core processes dominate over outer-core processes. Based on these findings, Fitzpatrick [47] showed in a study of TBB ranges from $0-6^{\circ}$ in intervals of $1^{\circ}$ that TBB data contain additional important convection information. Chen [45] applied predictors, including max, min, and mean TBB, within spatial regions to predict TC intensity. Chen's findings regarding TBB, however, applied characteristics identified in earlier literature and produced no uniform law. To extract TBB features more precisely and accurately, we designated a spatial region based on a correlation coefficient. The $0.05^{\circ} \times 0.05^{\circ}$ resolution of the FengYun satellite data used in this study is quite different from those used in previous studies and offers more detailed TBB information.

We analyzed the correlation between the satellite data and TC intensity. In Figure 3a, which shows the correlation coefficients (CCs) between TC intensity and TBB, there is a negative correlation in most areas; in other words, a lower TBB indicates stronger convection. Figure $3 \mathrm{~b}-\mathrm{e}$ show the maximum CCs 
between contemporary TBB data in the region and TC intensities at 6, 12, 18, and $24 \mathrm{~h}$ lead times, which were $-0.56,-0.52,-0.47$, and -0.41 , respectively. The CCs between the TBB of the TC center and the TC intensity became smaller with longer lead times. Figure 3b-e show significantly negative correlations in areas spreading to the west as the lead time extended. The most important part of each figure is its center, corresponding to the clearly visible eye of the TC, at which the absolute value of the CC was less than the absolute value of the CC in the surrounding areas. This phenomenon suggests that the $\mathrm{CC}$ in the eye decreases with longer lead times. TBB data obtained from IR (infrared radiation) imagery contain important information regarding TC intensity. The figures show that negative correlations occurred at approximately $4^{\circ}$ around each TC center, which was used to determine the TBB selection area radius of $4^{\circ}$ in the next step.
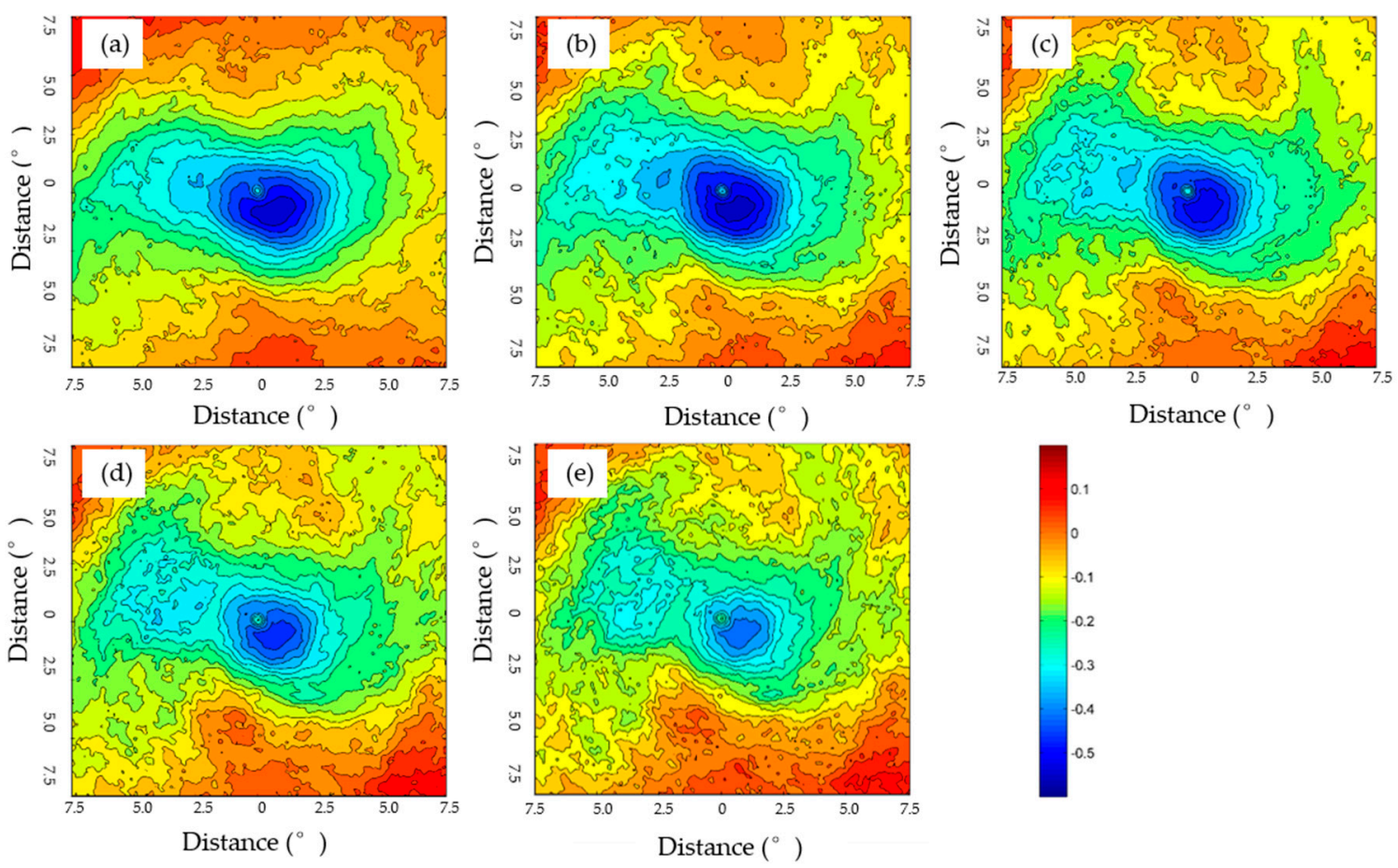

Figure 3. Correlations between South China Sea tropical cyclone (TC) intensity at various forecast lengths and the surrounding equivalent blackbody temperature (TBB). The center of each figure corresponds to the center of the TC. Forecast lengths depicted are (a) 0, (b) 6, (c) 12, (d) 18, (e) and $24 \mathrm{~h}$.

We then extracted satellite-based predictors from the TBB images in Figure 4. Fitzpatrick [47] established radial areas of $0-1^{\circ}, 0-2^{\circ}, 0-4^{\circ}, 0-6^{\circ}, 1-2^{\circ}, 2-4^{\circ}$, and $2-6^{\circ}$, with TBBs ranging from $193-218 \mathrm{~K}$ in $5 \mathrm{~K}$ increments. An examination of Figure 3 reveals that negative correlations were primarily distributed at $4^{\circ}$ around the TC center. In our adaptation of Fitzpatrick's methods, we processed radial annuli over $0-4^{\circ}$ from the TC center in $0.1^{\circ}$ increments. The corresponding TBB measurements were extracted from each of the 40 annuli. This approach allowed us to extract information regarding the TC in greater detail and to address the phenomenon of TC convection. Table 4 presents descriptions of the TBB-extracted factors. GAPRxTb_N represents the number of pixels in each radial area colder than a specified TBB, where Rx indicates the radial increment, Tb indicates the TBB value $(193 \mathrm{~K}, 198 \mathrm{~K}, 203 \mathrm{~K}$, $208 \mathrm{~K}, 213 \mathrm{~K}$, and $218 \mathrm{~K}$ ), and N indicates the location of rings. For example, the number of pixels in a $0-0.1^{\circ}$ radial area that were colder than $193 \mathrm{~K}$ are denoted as GAP0206_1, and the number of pixels in a $2-2.1^{\circ}$ radial area that were colder than $208 \mathrm{~K}$ are denoted GAP0206_21. GAP02max_N indicates the maximum TBB in each spatial area; for example, the maximum TBB in a $0-0.1^{\circ}$ radial area is designated GAP02max_1. GAP02min_N indicates the minimum TBB in each radial area; for example, the minimum TBB in a $0-0.1^{\circ}$ radial area is termed GAP02min_1. Similarly, GAP02mean_N indicates 
the mean TBB in each radial area; for example, the mean TBB in a $0-0.1^{\circ}$ radial area is designated as GAP02mean_1. Finally, the differences between the TBB value of the center and the maximum and minimum values are designated as GAP02maxc_N and GAP02minc_N, respectively.

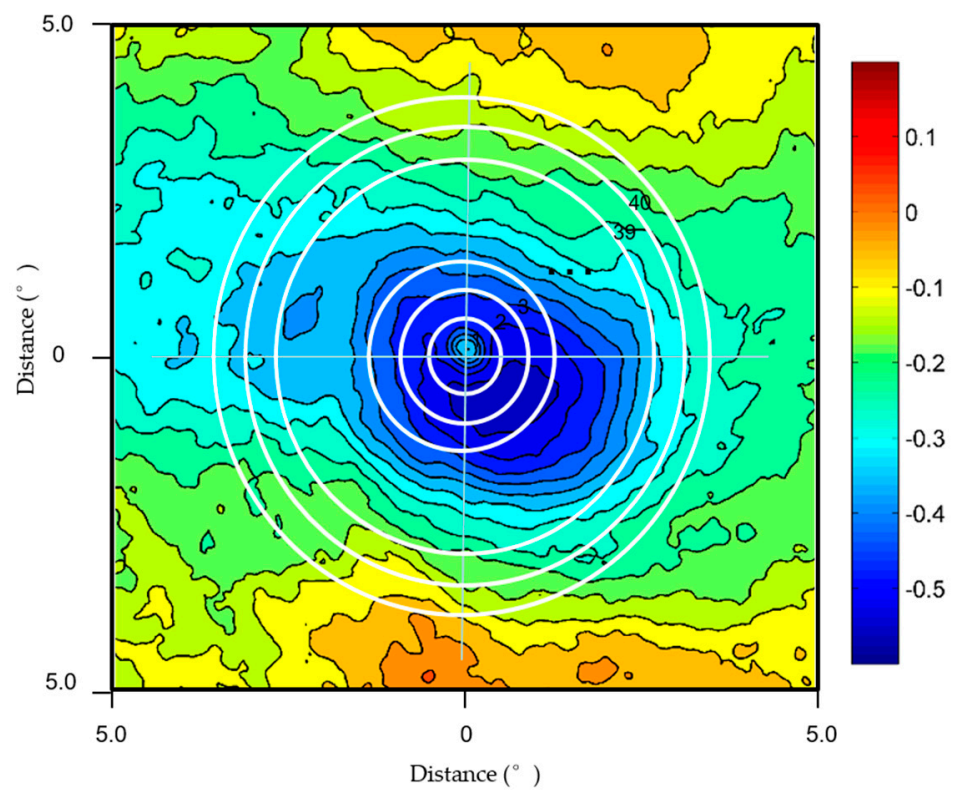

Figure 4. Annulus around the tropical cyclone (TC) center. The center of each figure corresponds to the TC eye. The innermost annulus is called the first annuli band, and the outermost annulus is called the 40th annuli band.

Table 4. Satellite-based predictors.

\begin{tabular}{|c|c|}
\hline Predictors & Description \\
\hline GAP0201_N & Number of infrared pixels in a radial area colder than $218 \mathrm{~K}$ at the $\mathrm{N}$ annuli band. \\
\hline GAP0202_N & Number of infrared pixels in a radial area colder than $213 \mathrm{~K}$ at the $\mathrm{N}$ annuli band. \\
\hline GAP0203_N & Number of infrared pixels in a radial area colder than $208 \mathrm{~K}$ at the $\mathrm{N}$ annuli band. \\
\hline GAP0204_N & Number of infrared pixels in a radial area colder than $203 \mathrm{~K}$ at the $\mathrm{N}$ annuli band. \\
\hline GAP0205_N & Number of infrared pixels in a radial area colder than $198 \mathrm{~K}$ at the $\mathrm{N}$ annuli band. \\
\hline GAP0206_N & Number of infrared pixels in a radial area colder than $193 \mathrm{~K}$ at the $\mathrm{N}$ annuli band. \\
\hline GAP02max_N & Max value of TBB in a radial area at the $\mathrm{N}$ annuli band. \\
\hline GAP02maxc_N & $\begin{array}{l}\text { Difference between the center TBB value and the max TBB within a radial area at } \\
\text { the } \mathrm{N} \text { annuli band. }\end{array}$ \\
\hline GAP02mean_N & Mean TBB in a radial area at the $\mathrm{N}$ annuli band. \\
\hline GAP02min_N & Min value of TBB in a radial area at the $\mathrm{N}$ annuli band. \\
\hline GAP02minc_N & $\begin{array}{l}\text { Difference between the center TBB value and the min TBB within a radial area at } \\
\text { the } \mathrm{N} \text { annuli band. }\end{array}$ \\
\hline GAP02stand_N & Standard deviation TBB in a radial area at the $\mathrm{N}$ annuli band. \\
\hline
\end{tabular}

\subsubsection{Parameters for Adjusting the TC Intensity Prediction Model}

The resulting XGBoost model contained many important parameters that required adjustments to fit different scenarios. These included the eta parameter, which was designed to reduce the individual feature weights, avoid overfitting, and apply shrinkage steps in process updates; the gamma parameter, which was used to further partition the tree leaf nodes to reduce losses; the max_depth parameter representing the maximum depth of a tree; and the min_child_weight parameter, representing the minimum weight coefficient of the leaf nodes. We selected the best parameters for a $6 \mathrm{~h}$ lead time prediction model, corresponding to the eta, gamma, max_depth, and min_child_weight values of $0.1,0.8,8$, and 4 , respectively; the best parameters for 12 and $18 \mathrm{~h}$ lead times were determined to be 
eta, gamma, max_depth, and min_child_weight values of $0.1,0.8,6$, and 4 , respectively; and the best parameters for a $24 \mathrm{~h}$ lead time were found to be eta, gamma, max_depth, and min_child_weight values of $0.1,0.8,6$, and 2 , respectively.

\subsubsection{Experiment}

Table 5 lists input and output parameters of the three models evaluated in the study. The input parameters include, CLIPER factors, environmental predictors, and satellite-based predictors. To assess various extraction methods for satellite-based predictors, we designed two methods to extract satellite-based predictors from brightness temperature images.

The first model, A1, served as a control in which CLIPER and environmental predictors were used as input parameters. The second model (A2) was developed using the XGBoost model based on the input parameters of the A1 model plus the satellite-based predictors. The average satellite-based predictor values (abbreviated as S_mean) were calculated within a range of $4^{\circ}$ from the TC center. The satellite-based predictors were extracted via the traditional method widely used in the SHIPS model [7]. The third model (A3) was also developed using the XGBoost model, based on the input parameters of the A1 model plus the satellite-based predictors. However, the extraction method for the satellite-based predictors divided each image into 40 annuli bands of 2 pixels each around the TC center. For each band, the mean, standard deviation, minimum, maximum, difference between the center TBB value and the max TBB within a radial area, difference between the center TBB value and the min TBB within a radial area, number of infrared pixels in a radial area colder than $218 \mathrm{~K}$, number of infrared pixels in a radial area colder than $213 \mathrm{~K}$, number of infrared pixels in a radial area colder than $208 \mathrm{~K}$, number of infrared pixels in a radial area colder than $203 \mathrm{~K}$, number of infrared pixels in a radial area colder than $198 \mathrm{~K}$, and number of infrared pixels in a radial area colder than $193 \mathrm{~K}$, were calculated. Using this method, referred to as the "ring segmentation method" (S_2), $480(12 \times 40)$ predictors were extracted.

As shown in Table 5, each of these models contained different input parameters. The output parameter was TC intensity at 6, 12, 18, and $24 \mathrm{~h}$. In this study, the TC samples from 2006-2012 were used for model training, and the remaining samples, from 2013-2017, were used for verification.

Table 5. Input and output parameters of the three prediction models.

\begin{tabular}{cccc}
\hline Model & Input Parameters & Type & Output Parameters \\
\hline A1 & CLIPER + environmental predictors & & TC intensity $(\mathrm{t}+\Delta \mathrm{t})$ \\
A2 & A1 + S_mean & XGBoost & $\Delta t=6,12,18$, and 24 h, respectively. \\
A3 & A1 + S_2 & & \\
\hline
\end{tabular}

To evaluate the performance of each XGBoost model corresponding to a given lead time during the training and validation periods, we used the CC (correlation coefficient), mean absolute error (MAE), and normalized root mean square error (NRMSE).

\section{Results}

\subsection{Feature Selection}

To verify the relationship between the statistical information extracted from 40 circular bands and the TC intensity, a scatter plot of the satellite predictors and the TC intensity was generated using the correlation coefficient, as shown in Figure 5. The results showed that the number of pixels colder than $218,213,208,203,198$, and $193 \mathrm{~K}$ in each ring had a positive correlation with TC intensity. As distance from the TC center increased, the correlation coefficient first increased and then decreased, indicating that the number of pixels colder than 218, 213, 208, 203, 198, and $193 \mathrm{~K}$ in each ring was indicative of the TC intensity. The maximum brightness temperature value in each ring had a negative correlation with the TC intensity. As the distance from the TC center increased, the correlation 
coefficient of brightness temperature and TC intensity first increased and then decreased, indicating that the maximum brightness temperature value in each ring could indicate the strength of the relationship with TC intensity.

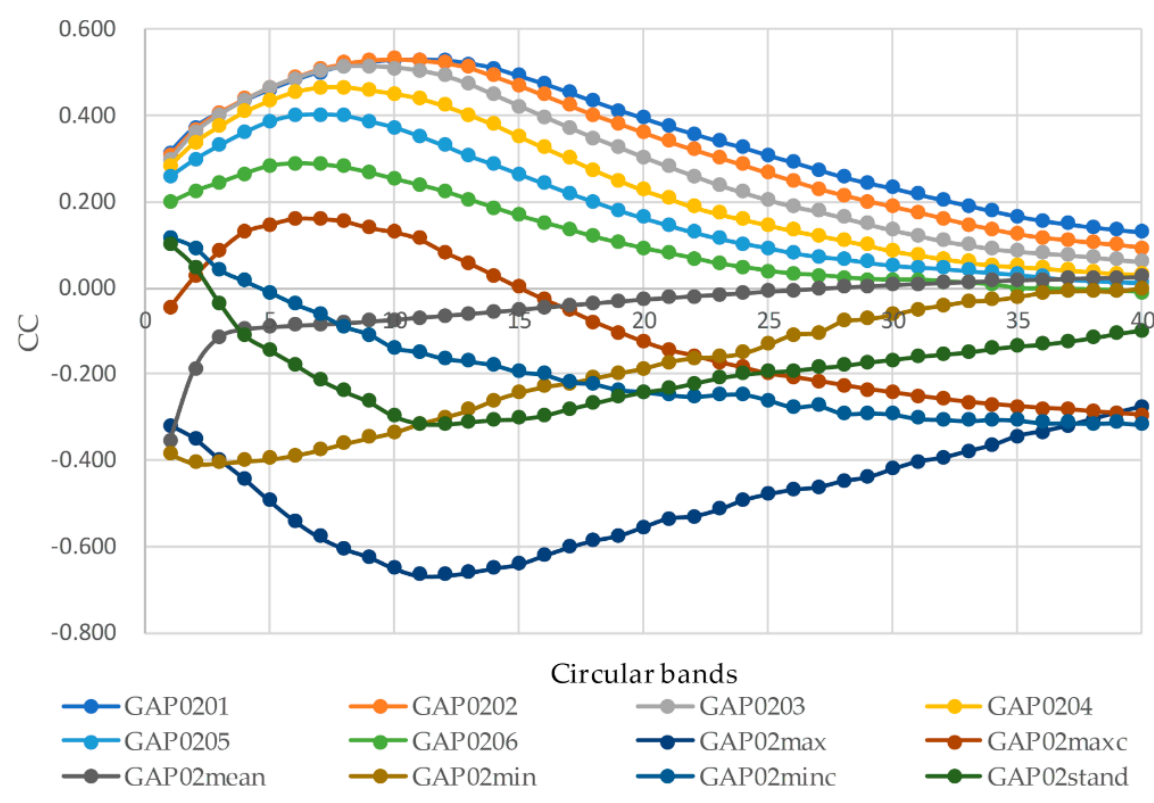

Figure 5. Correlation coefficients (CCs) between 480 predictors and tropical cyclone (TC) intensity.

The TBB information was fully extracted via the ring segmentation method, and 480 satellite predictors were obtained. However, among these 480 predictors, some predictor information was duplicated, or was not related to TC intensity. To properly control the number of selected factors, 10 prediction factors were selected as the model input based on the feature ranking of the learning model. The filtered information gain ranking results are shown in Table 6. The smaller the serial number, the higher the correlation between the predictor and the prediction result. The sorting results indicate that different satellite predictors were best suited for TC intensity prediction models with different lead times. The following main findings were found: (1) for a $6 \mathrm{~h}$ lead time, the selected satellite-based predictors included the maximum TBB in the 1.0-1.5 $5^{\circ}$ adial area, the maximum TBB in the $1.6-1.7^{\circ}$ radial area, the pixels colder than $218 \mathrm{~K}$ at radii of $0.5-0.6^{\circ}$ and $0.7-0.8^{\circ}$, the pixels at radii of $0.5-0.6^{\circ}$ colder than $213 \mathrm{~K}$, and the pixels at radii of $0.7-0.8^{\circ}$ colder than $208 \mathrm{~K}$; (2) for a $12 \mathrm{~h}$ lead time, the selected satellite predictors included the maximum TBB in the $1.0-1.3^{\circ}$ radial area, the maximum TBB in the $1.4-1.6^{\circ}$ radial area, the pixels colder than $213 \mathrm{~K}$ at radii of $0.5-0.6^{\circ}$, and the pixels colder than $208 \mathrm{~K}$ at radii of $0.7-1.0^{\circ}$; (3) for an $18 \mathrm{~h}$ lead time, the selected satellite predictors included the maximum TBB in the $1.0-1.3^{\circ}$ radial area, the maximum TBB in the $1.5-1.6^{\circ}$ radial area, the pixels colder than $218 \mathrm{~K}$ at radii of $0.7-0.8^{\circ}$, the pixels colder than $213 \mathrm{~K}$ at radii of $0.5-0.6^{\circ}$ and $0.7-0.8^{\circ}$, the pixels colder than $208 \mathrm{~K}$ at radii of $0.7-0.8^{\circ}$, and the pixels colder than $203 \mathrm{~K}$ at radii of $0.9-1.0^{\circ}$; (4) for a $24 \mathrm{~h}$ lead time, the selected satellite predictors included the maximum TBB in the $1.0-1.1^{\circ}, 1.2-1.4^{\circ}, 1.5-1.6^{\circ}$, and $1.7-1.8^{\circ}$ radial areas, the pixels colder than $218 \mathrm{~K}$ at radii of $0.6-0.8^{\circ}$ and $0.9-1.0^{\circ}$, and the pixels colder than $208 \mathrm{~K}$ at radii of $0.7-0.8^{\circ}$. No good predictors were found outside of the first 20 rings $\left(2.0^{\circ}\right)$ and within the first five rings $\left(0.5^{\circ}\right)$; this supports the analysis utilized in other objective schemes such as the Advanced Dvorak Technique [50]. The aforementioned finding suggests that most of the information regarding TC intensity that can be obtained using IR imagery is within the inner core region, and this indicates that once the eye appears, less relevant information is available for TC intensity prediction. Thus, the selected satellite parameters were located in rings 6-17 $\left(0.5-1.7^{\circ}\right.$ from the TC center) and included the number of pixels in these rings that were colder than $218,213,208$, and $203 \mathrm{~K}$. 
Table 6. Selected satellite factors at lead times of $6,12,18$, and $24 \mathrm{~h}$.

\begin{tabular}{cccccc}
\hline No. & Time & $\mathbf{6} \mathbf{h}$ & $\mathbf{1 2} \mathbf{h}$ & $\mathbf{1 8} \mathbf{h}$ & $\mathbf{2 4} \mathbf{h}$ \\
\hline & & & & & \\
& & GAP02max_13 & GAP02max_12 & GAP0203_8 & GAP0201_7 \\
2 & GAP02max_11 & GAP02max_13 & GAP02max_12 & GAP0203_8 \\
3 & GAP0203_8 & GAP02max_11 & GAP02max_13 & GAP02max_18 \\
4 & GAP02max_14 & GAP0203_8 & GAP02max_16 & GAP0201_10 \\
5 & GAP0201_6 & GAP02max_16 & GAP0201_8 & GAP02max_13 \\
6 & GAP02max_15 & GAP0202_6 & GAP0202_8 & GAP02max_16 \\
7 & GAP0201_8 & GAP0203_10 & GAP02max_11 & GAP0201_6 \\
8 & GAP0202_6 & GAP02stand_2 & GAP0204_10 & GAP0201_8 \\
9 & GAP02max_12 & GAP0203_7 & GAP0202_6 & GAP02max_11 \\
10 & GAP02max_17 & GAP02max_15 & GAP02stand_1 & GAP02max_14 \\
\hline
\end{tabular}

\subsection{TC intensity Prediction Accuracy}

After the three types of predictors had been processed, the TC intensity prediction model was run. This section describes the training results of each model. The results concerning the test samples in the XGBoost model are introduced first, and then the prediction results for each lead time are presented.

TC intensity information from the South China Sea from 2006 to 2012 was used as training data for models A1, A2, and A3, and the TC intensity from 2013 to 2017 was predicted and verified. Table 7 shows the TC intensity results (CCs, MAE, and NRMSE) for 6, 12, 18, and $24 \mathrm{~h}$ lead times. The best model for each lead time is indicated in bold. The A3 model (A1 + S_2) and A2 model (A1 + S_mean) produced better forecasts than the A1 model. Among the models, A3 had the lowest MAE and NRMSE values and the highest $C C$ values. For all lead times, the MAE of model A3 was lower than that of both $\mathrm{A} 1$ and A2. These results indicate that the forecast skills of models A3 and A2, with their satellite-based predictors, were better than those of A1, which did not use satellite-based predictors. As shown in the table, as lead times increased, the MAE and NRMSE values became larger and the CC values became smaller. For example, in the A2 model at $6,12,18$, and $24 \mathrm{~h}$ lead times, the MAE values were 2.15 $\mathrm{m} / \mathrm{s}, 3.35 \mathrm{~m} / \mathrm{s}, 4.19 \mathrm{~m} / \mathrm{s}$, and $4.96 \mathrm{~m} / \mathrm{s}$, and the CC values were $0.94,0.86,0.81$, and 0.73 , respectively. The NRMSE values were 5.40,8.33, 9.58, and 10.80. The $6 \mathrm{~h} C \mathrm{C}$ for model A3 was 0.95 , and its $6 \mathrm{~h}$ MAE was $2.14 \mathrm{~m} / \mathrm{s}$. Its $6 \mathrm{~h}$ NRMSE was $5.28 \%$ lower than that of model A2. The $12 \mathrm{~h} \mathrm{CC}$ for model A3 was approximately 0.87 . The $12 \mathrm{~h}$ MAE for model A3 was $3.29 \mathrm{~m} / \mathrm{s}$ lower than that of model A1. The $18 \mathrm{~h} \mathrm{CC}$ for model A3 was approximately 0.82 . The $24 \mathrm{~h}$ MAE for model A3 was approximately $4.71 \mathrm{~m} / \mathrm{s}$, and A3 produced the lowest MAE value for a $24 \mathrm{~h}$ lead time. These results suggest that the combination of predictors in A3 is well suited to forecasting TC intensity at lead times of $6,12,18$, and $24 \mathrm{~h}$. For each model, the CC values decreased with time, while the MAE and NRMSE values both increased. The CCs of model A3 were approximately $0.95,0.87,0.82$, and 0.75 at lead times of 6,12 , 18 , and $24 \mathrm{~h}$, respectively. The MAEs of all models ranged from 2.14 to $2.20 \mathrm{~m} / \mathrm{s}, 3.29$ to $3.56 \mathrm{~m} / \mathrm{s}, 4.11$ to $4.45 \mathrm{~m} / \mathrm{s}$, and 4.71 to $4.96 \mathrm{~m} / \mathrm{s}$, at lead times of 612,18 , and $24 \mathrm{~h}$, respectively. The NRMSEs of all models ranged from 5.28 to $5.68 \mathrm{~m} / \mathrm{s}, 8.19$ to $9.19 \mathrm{~m} / \mathrm{s}, 9.42$ to $10.69 \mathrm{~m} / \mathrm{s}$, and 10.51 to $11.33 \mathrm{~m} / \mathrm{s}$ at lead times of 612,18 , and $24 \mathrm{~h}$, respectively. 
Table 7. Errors of the TC intensity at $6,12,18$, and $24 \mathrm{~h}$ lead times.

\begin{tabular}{ccccc}
\hline \multirow{2}{*}{ Lead Time } & Models & \multicolumn{3}{c}{ Accuracy } \\
\cline { 3 - 5 } & & MAE & NRMSE & CC \\
\hline \multirow{3}{*}{$6 \mathrm{~h}$} & A1 & 2.20 & 5.68 & 0.94 \\
& A2 & 2.15 & 5.40 & 0.94 \\
& A3 & $\mathbf{2 . 1 4}$ & $\mathbf{5 . 2 8}$ & $\mathbf{0 . 9 5}$ \\
\hline \multirow{3}{*}{$12 \mathrm{~h}$} & A1 & 3.56 & 9.19 & 0.82 \\
& A2 & 3.35 & 8.33 & 0.86 \\
& A3 & $\mathbf{3 . 2 9}$ & $\mathbf{8 . 1 9}$ & $\mathbf{0 . 8 7}$ \\
\hline \multirow{3}{*}{$24 \mathrm{~h}$} & A1 & 4.45 & 10.69 & 0.75 \\
& A2 & 4.19 & 9.58 & 0.81 \\
& A3 & $\mathbf{4 . 1 1}$ & $\mathbf{9 . 4 2}$ & $\mathbf{0 . 8 2}$ \\
\hline \multirow{2}{*}{24} & A1 & 4.96 & 11.33 & 0.69 \\
& A2 & 4.96 & 10.80 & 0.73 \\
& A3 & $\mathbf{4 . 7 1}$ & $\mathbf{1 0 . 5 1}$ & $\mathbf{0 . 7 5}$ \\
\hline
\end{tabular}

Note: MAE: mean absolute error; NRMSE: normalized root mean square error; CC: correlation coefficient.

\subsection{Comparison of the Different Models}

Figure 6 (A1_6, A2_6, and A3_6) shows scatterplots of the intensity predictions produced by the three models and the actual intensity values at $6,12,18$, and $24 \mathrm{~h}$ lead times. The overall model fit between the predicted values of model A1 and the actual values was fairly strong with a $\mathrm{R}^{2}$ of 0.88 , indicating that the model had a good ability to predict TC intensity. Model A2 added averaged satellite data to the predictors considered by model $A 1$, and its $\mathrm{R}^{2}$ and relative bias were slightly improved over that of the first model. Compared with model A1, the $\mathrm{R}^{2}$ and relative bias of model A3 increased to 0.91 and the relative bias of model A3 decreased to $8.62 \%$. The results show that the prediction ability of model A3 with a $6 \mathrm{~h}$ lead time was considerably better than those of models A1 and A2.

Figure 6 (A1_12, A2_12, and A3_12) shows scatterplots of the intensities predicted by the models at a $12 \mathrm{~h}$ lead time and the actual intensity values. The overall model fit between model A1's predicted values and the actual values was fairly good, with a $\mathrm{R}^{2}$ of 0.73 . Model A2's $\mathrm{R}^{2}$ was 0.74 , representing a slight improvement over that of A1. The $\mathrm{R}^{2}$ of model A3 improved to 0.82 . The relative bias of model A3 decreased to $12.57 \%$. In the figure, the fitting line of model A3 is closer to that of the actual values (the red line), than those of models A1 and A2. These results show that the prediction ability of model $\mathrm{A} 3$ at a $12 \mathrm{~h}$ lead time is significantly better than that of models A1 and A2.

Figure 6 (A1_18, A2_18, and A3_18) shows scatterplots of the predicted intensity values of the three models with an $18 \mathrm{~h}$ lead time and the actual values. Model A1 achieved a $\mathrm{R}^{2}$ of 0.61 , which shows that the model had a good ability to predict TC intensity. Model A2's $\mathrm{R}^{2}$ improved slightly to 0.66, while A3's $\mathrm{R}^{2}$ increased to 0.73 . Model A2's relative bias decreased slightly to $17.96 \%$, while A3's relative bias decreased to $16.48 \%$. The fitting line of model A3 was near that of the actual values (the red line) than were those of models A1 and A2. Thus, model A3 had a significantly better predictive ability than that of models $\mathrm{A} 1$ and $\mathrm{A} 2$ at an $18 \mathrm{~h}$ lead time.

Finally, Figure 6 (A1_24, A2_24, and A3_24) shows scatterplots of the predicted and actual intensity values at a $24 \mathrm{~h}$ lead time. A1 achieved a $\mathrm{R}^{2}$ of only 0.51 , indicating a poor ability to predict $\mathrm{TC}$ intensity. Model A2's $\mathrm{R}^{2}$ was slightly improved, at 0.56, and that of model A3 increased to 0.63. Model A2's relative bias was slightly decreased, at 21.93\%, and that of model A3 decreased to 19.04\%. The fitting line of model A3 was closer to that of the actual values (red line) than were those of models A1 and A2. The results demonstrate that the predictive ability of model A3 at a $24 \mathrm{~h}$ lead time is significantly better than that of models A1 and A2.

Table 8 presents further comparison of the accuracy of the three models, including relative bias and $\mathrm{R}^{2}$ values. In each case, A3 was found to offer the best perform for TC intensity prediction. 
Table 8. Comparative analysis of TC intensity prediction at 6, 12, 18, and $24 \mathrm{~h}$ lead times.

\begin{tabular}{cccc}
\hline Lead Time & Model & Relative Bias (\%) & $\mathbf{R}^{\mathbf{2}}$ \\
\hline \multirow{3}{*}{$6 \mathrm{~h}$} & A1 & 9.58 & 0.88 \\
& A2 & 9.22 & 0.88 \\
& A3 & $\mathbf{8 . 6 2}$ & $\mathbf{0 . 9 1}$ \\
\hline \multirow{3}{*}{$12 \mathrm{~h}$} & A1 & 14.88 & 0.73 \\
& A2 & 13.76 & 0.74 \\
& A3 & $\mathbf{1 2 . 5 7}$ & $\mathbf{0 . 8 2}$ \\
\hline \multirow{3}{*}{$18 \mathrm{~h}$} & A1 & 20.99 & 0.61 \\
& A2 & 17.96 & 0.66 \\
& A3 & $\mathbf{1 6 . 4 8}$ & $\mathbf{0 . 7 3}$ \\
\hline \multirow{3}{*}{$24 \mathrm{~h}$} & A1 & 23.94 & 0.51 \\
& A2 & 21.93 & 0.56 \\
& A3 & $\mathbf{1 9 . 0 4}$ & $\mathbf{0 . 6 3}$ \\
\hline
\end{tabular}
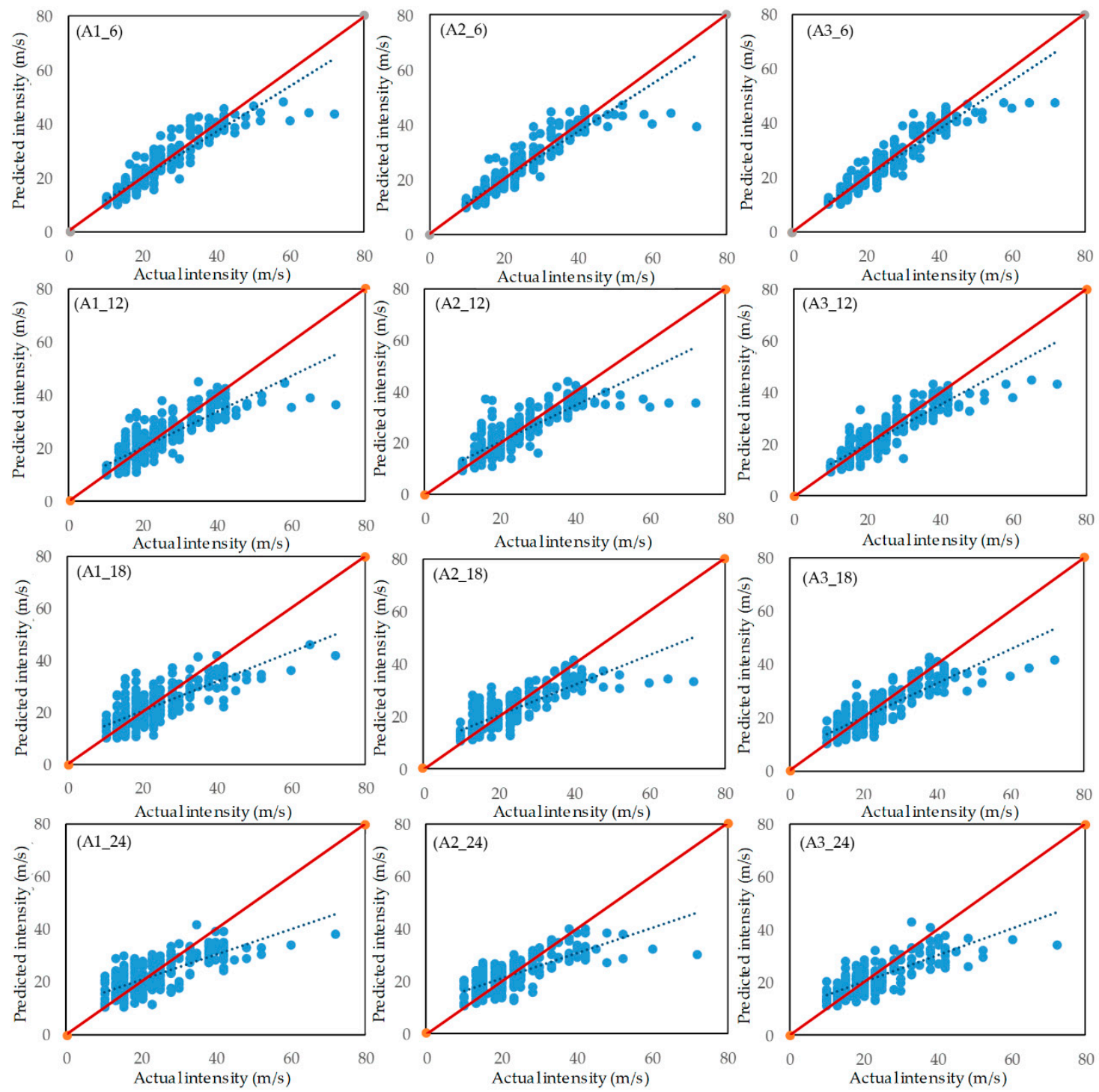

Figure 6. Scatter plots of the actual intensity and the intensities predicted by models A1, A2, and A3 at $6,12,18$, and $24 \mathrm{~h}$ lead times. Actual intensity values are shown along the abscissa axes and predicted intensity values along the ordinate axes. 


\subsection{Forecast Skill at Different Intensities}

\subsubsection{Long Short-Term Memory (LSTM) Model}

The long short-term memory (LSTM) model introduces an input gate, output gate and forgetting gate in each neuron of a recurrent neural network, to describe and predict the long-term dependence of time series data [51]. The model has been applied in many fields, such as tropical cyclone path prediction [52], traffic volume prediction [53], and future land-use prediction [54], demonstrating its popularity as a time series-based prediction model.

Figure 7 shows the structure of the LSTM model. The main components of the model include the input gate $\left(i_{t}\right)$, output gate $\left(o_{t}\right)$, update gate $\left(i m_{t}\right)$, forget gate $\left(f_{t}\right)$, cell memory $\left(C_{t}\right)$, and cell output $\left(h_{t}\right)$.

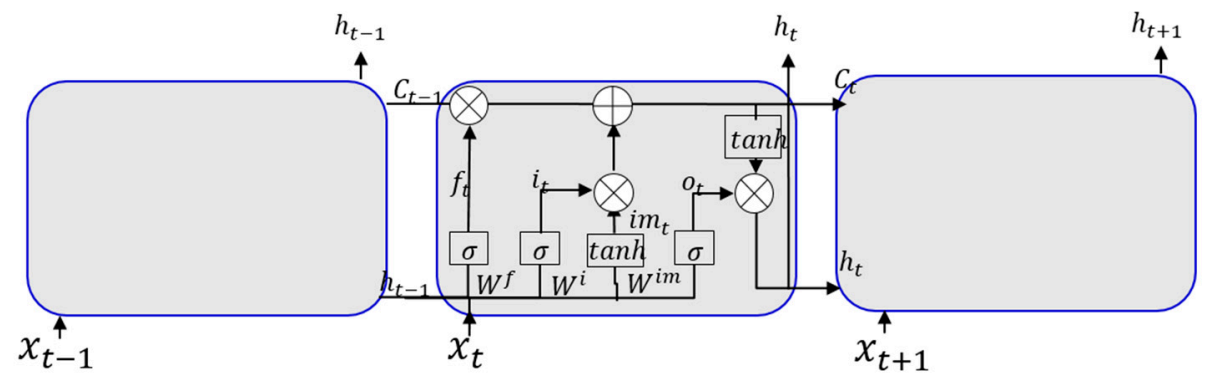

Figure 7. Structure of the long short-term memory (LSTM) model.

$W^{i}, W^{f}, W^{i m}$, and $W^{o}$ represent the weight of the input gate, forget gate, update gate, and output gate, respectively. $b^{(i)}, b^{(f)}, b^{(i m)}$, and $b^{(o)}$ represent the bias of the input gate, forget gate, update gate, and output gate, respectively. $\sigma$ represents sigmoid activation, and tanh represents hyperbolic tangent activation. The main operative processes of the model are as follows:

$$
\begin{gathered}
f_{t}=\sigma\left(W^{f} \cdot\left[h_{t-1}, x_{t}\right]+b^{(f)}\right) \\
i_{t}=\sigma\left(W^{i} \cdot\left[h_{t-1}, x_{t}\right]+b^{(i)}\right) \\
i m_{t}=\tanh \left(W^{i m} \cdot\left[h_{t-1}, x_{t}\right]+b^{(i m)}\right) \\
C_{t}=i_{t} \cdot i m_{t}+f_{t} \cdot C_{t-1} \\
o_{t}=\sigma\left(W^{o} \cdot\left[h_{t-1}, x_{t}\right]+b^{(o)}\right) \\
h_{t}=o_{t} \cdot \tanh \left(C_{t}\right)
\end{gathered}
$$

where "." represents the point multiplication operation of two vectors.

\subsubsection{Comparative Analysis}

To further study the prediction performance of model A3, we used the LSTM model to predict the intensity of TCs in the South China Sea, using the same predictors (hereafter referred to as the LSTM-TCIPS; model A3 will hereafter be referred to as XGB-TCIPS). As these two models yielded different results for TCs with different intensities, the TC intensities recorded in the South China Sea in 2013-2017 were used to analyze the models' predictive abilities according to different TC intensity types at $6,12,18$, and $24 \mathrm{~h}$ lead times.

Tables 9-12 compare the performances of the two models. It was found that at increased lead times, the LSTM-TCIPS model is more suitable for forecasting higher intensity levels, indicating that this model is more suitable for longer-term TC prediction, whereas the XGB-TCIPS model is better suited for short-term predictions. These conclusions were based on the following: (1) at a $6 \mathrm{~h}$ lead time, the XGB-TCIPS model had a smaller average absolute error than did the LSTM-TCIPS model for 
TCs of all intensity levels, and the XGB-TCIPS model was suitable for all intensity types. (2) At a $12 \mathrm{~h}$ lead time, the XGB-TCIPS model was more suitable for the prediction of tropical depressions, severe tropical storms, typhoons, and strong typhoons, whereas the LSTM-TCIPS model was better suited for the prediction of super typhoons. (3) At an $18 \mathrm{~h}$ lead time, the XGB-TCIPS model was better suited for the prediction of tropical depressions, severe tropical storms, typhoons, strong typhoons, and super typhoons, whereas LSTM-TCIPS was better suited for the prediction of tropical storms. (4) For a $24 \mathrm{~h}$ lead time, the XGB-TCIPS model was more suitable for the prediction of tropical depressions, typhoons, and strong typhoons, and the LSTM-TCIPS model was better suited for the prediction of tropical storms, severe tropical storms, and super typhoons.

Table 9. LSTM and XGBoost model errors for different tropical cyclone intensity levels at a $6 \mathrm{~h}$ lead time.

\begin{tabular}{ccccc}
\hline \multirow{2}{*}{ Type } & \multicolumn{2}{c}{ LSTM } & \multicolumn{2}{c}{ XGBoost } \\
\cline { 2 - 5 } & MAE (m/s) & NRMSE & MAE (m/s) & NRMSE \\
\hline Tropical depression & 1.56 & 3.10 & 1.45 & 2.9 \\
Tropical storm & 2.07 & 4.05 & 1.89 & 4.21 \\
Severe tropical storm & 3.48 & 6.62 & 2.34 & 5.49 \\
Typhoon & 6.91 & 12.19 & 2.99 & 5.87 \\
Severe typhoon & 12.23 & 20.49 & 2.74 & 5.36 \\
Super typhoon & 19.77 & 32.73 & 13.91 & 24.6 \\
\hline
\end{tabular}

Note: LSTM: long short-term memory; MAE: mean absolute error; NRMSE: normalized root mean square error.

Table 10. LSTM and XGBoost model errors for different tropical cyclone intensity levels at a $12 \mathrm{~h}$ lead time.

\begin{tabular}{ccccc}
\hline \multirow{2}{*}{ Type } & \multicolumn{2}{c}{ LSTM } & \multicolumn{2}{c}{ XGBoost } \\
\cline { 2 - 5 } & MAE (m/s) & NRMSE & MAE (m/s) & NRMSE \\
\hline Tropical depression & 2.55 & 6.17 & 2.17 & 5.46 \\
Tropical storm & 2.72 & 5.65 & 2.66 & 6.14 \\
Severe tropical storm & 4.25 & 8.03 & 3.69 & 7.81 \\
Typhoon & 5.14 & 10.51 & 4.01 & 7.81 \\
Severe typhoon & 9.78 & 18.44 & 6.35 & 12.43 \\
Super typhoon & 18.12 & 31.03 & 20.15 & 34.66 \\
\hline
\end{tabular}

Note: LSTM: long short-term memory; MAE: mean absolute error; NRMSE: normalized root mean square error.

Table 11. LSTM and XGBoost model errors for different tropical cyclone intensity levels at an $18 \mathrm{~h}$ lead time.

\begin{tabular}{ccccc}
\hline \multirow{2}{*}{ Type } & \multicolumn{2}{c}{ LSTM } & \multicolumn{2}{c}{ XGBoost } \\
\cline { 2 - 5 } & MAE (m/s) & NRMSE & MAE (m/s) & NRMSE \\
\hline Tropical depression & 3.44 & 8.29 & 3.11 & 7.43 \\
Tropical storm & 3.22 & 6.67 & 3.42 & 7.31 \\
Severe tropical storm & 4.74 & 9.23 & 4.24 & 8.12 \\
Typhoon & 6.33 & 12.85 & 4.17 & 8.41 \\
Severe typhoon & 12.03 & 22.65 & 9.50 & 16.79 \\
Super typhoon & 21.69 & 36.12 & 21.20 & 35.39 \\
\hline
\end{tabular}

Note: LSTM: long short-term memory; MAE: mean absolute error; NRMSE: normalized root mean square error. 
Table 12. LSTM and XGBoost model errors for different tropical cyclone intensity levels at a $24 \mathrm{~h}$ lead time.

\begin{tabular}{ccccc}
\hline \multirow{2}{*}{ Type } & \multicolumn{2}{c}{ LSTM } & \multicolumn{2}{c}{ XGBoost } \\
\cline { 2 - 5 } & MAE (m/s) & NRMSE & MAE (m/s) & NRMSE \\
\hline Tropical depression & 4.79 & 10.61 & 3.9 & 8.94 \\
Tropical storm & 3.67 & 7.47 & 3.82 & 7.95 \\
Severe tropical storm & 4.51 & 8.37 & 4.52 & 8.78 \\
Typhoon & 6.66 & 14.19 & 5.15 & 10.58 \\
Severe typhoon & 13.07 & 24.25 & 10.55 & 18.34 \\
Super typhoon & 22.04 & 36.24 & 22.61 & 37.86 \\
\hline
\end{tabular}

Note: LSTM: long short-term memory; MAE: mean absolute error; NRMSE: normalized root mean square error.

\section{Discussion}

In this study, we developed a new TC intensity prediction model that is based on the XGBoost model; the proposed model integrates climatology and persistence, environmental, and satellite-based predictors. Climatology and persistence factors can provide a more detailed description of TC motion features. Environmental factors can reflect the synoptic features of TC in the South China Sea. The TBB features are used to characterize the structure and the development of convection. Our experimental results demonstrate that satellite data can improve the accuracy of TC intensity prediction, particularly when TBB is used as input data. The MAE of model A2, which included S_mean satellite predictors that were not considered in A1, produced improvements of $2.27 \%, 5.90 \%, 5.84 \%$, and $0.00 \%$ over the MAEs of A1 at lead times of 6, 12, 18, and $24 \mathrm{~h}$. However, the MAE of model A3, which includes satellite predictors extracted via method S_2, produced MAE improvements of $2.73 \%, 7.58 \%, 7.64 \%$, and $5.04 \%$ for lead times of $6,12,18$, and 24 h over those of model A1. The conclusions of model A3 were also consistent with those of STIPER (Statistical Typhoon Intensity Prediction including surface Evaporation and inner core Rainfall) [9].

In this study, we developed a new extraction method (the "ring segmentation method") for satellite image data. Our experimental results suggested that the ring segmentation method can improve the accuracy of TC intensity prediction. The MAE of model A3 (A1 + satellite-based predictors extracted via ring segmentation) decreased by $0.47 \%, 1.79 \%, 1.91 \%$, and $5.04 \%$ at $6,12,18$, and $24 \mathrm{~h}$ lead times, respectively, compared to those of model A2 (A1 + satellite-based predictors extracted as mean values). There are two possible reasons for this. The first is that high-resolution FY satellite data can provide detailed information on TC structure. For example, we noted that the TC intensity attributes extracted from TBB features in FY-2 images included the TC cloud-top convection strength, distribution, and size, all of which are closely related to TC intensity. The absolute CC values between the TBB values at the TC centers and the TC intensity become smaller at longer lead times. Muramatsu [55] suggested that TBB has a very high correlation with TC intensity and is therefore very important in TC prediction. High-resolution FY-2 satellite data allow TBB_C data to be extracted at smaller intervals $\left(0.1^{\circ}\right)$, allowing us to obtain 480 features from the TBB images by applying Fitzpatrick's extraction method [47]. The factors related to TC intensity at lead times of $6,12,18$, and $24 \mathrm{~h}$ were extracted using the ring segmentation method, and the small intervals at which these data could be extracted provided detailed descriptions of the relationships between the TBB and TC intensity. The pixels colder than a particular TBB at given radii were also helpful in improving TC intensity prediction. Pixels colder than $253.15 \mathrm{~K}$ at a radius of $2^{\circ}$ were found to be a noteworthy predictor of intensity [56]. At a $24 \mathrm{~h}$ lead time, the highest predictive value was found for pixels colder than $218 \mathrm{~K}$ at radii of $0.6-0.7^{\circ}$. Pixels colder than $208 \mathrm{~K}$ represent a deep convective region [57]. At an $18 \mathrm{~h}$ lead time, the number of pixels colder than $208 \mathrm{~K}$ at radii of $0.7-0.8^{\circ}$ was the most significant predictor of TC intensity, indicating that deep convection regions are also very important for predicting TC intensity at lead times close to $18 \mathrm{~h}$. In another study, the highest correlation between the maximum TBB and TB intensity was found in the 
$1.4^{\circ}$ radial area at a $0-36 \mathrm{~h}$ lead time [45]. In this study, the highest correlation between TBB and TC intensity was found in the 1.1-1.5 radial area at a $6-12 \mathrm{~h}$ lead time. Because our extraction method allowed us to employ high-resolution FY-2 satellite data, our results can be considered more precise than those found in previous studies.

The second reason that the ring segmentation method led to better results is that the XGBoost model allows multi-predictor input. In this study, we assessed the response of the model to different combinations of input features related to TC intensity in the South China Sea, such as inner-core convection, climatology and persistence factors, and environmental factors. The resulting combination of predictors obtained from the TBB features derived from the FY-2 satellite data, the best track data taken from the CMA-STI, and environmental information obtained from the ERA-Interim dataset were then used to build the final model. Because the model primarily uses randomly selected features, each tree can be built from a random set of features rather than the overall set. Combining all trees constructed in this manner led to the most accurate predictions. In this study, we used approximately 100 predictors that did not produce any serious over-fitting in the XGBoost model, because an appropriate scale was used to select the eta hyperparameters. However, we did identify one limitation in our proposed model. Its errors when predicting the intensity of very strong storms in the "severe typhoon" and "super typhoon" intensity categories were substantially large at lead times of $6,12,18,24 \mathrm{~h}$. This limitation is likely attributable to the relatively low number of samples concerning high-intensity TC events, leading to larger model errors concerning these types of storms. Figure 8 shows the frequencies of different TC intensities in the South China Sea from 2006 to 2012. Cyclones in the severe typhoon and super typhoon categories have the lowest occurrence in the training data. Owing to the lack of training samples, the accuracy of the model, with regard to severe typhoons and super typhoons, is low.

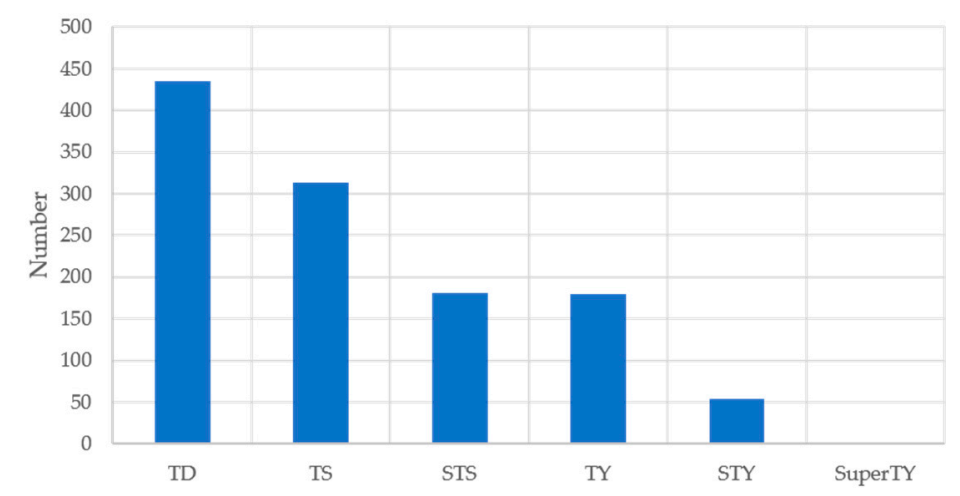

Figure 8. Frequencies of tropical cyclones of different intensities in the South China Sea from 2006 to 2012. TD: Tropical depression; TS: tropical storm; STS: severe tropical storm; TY: Typhoon; STY: Severe typhoon; SuperTY: Super typhoon.

The XGBoost method and the LSTM method can both predict TC intensity from a non-linear perspective. The XGBoost method essentially incorporates the XGBoost algorithm into the TC intensity prediction model, which improves the average absolute error of the existing TC intensity model predictions. The combination of feature selection and the spatio-temporal consideration of the LSTM model can also improve TC intensity predictions. The performance of each of the models seems to be dependent on lead time; the XGBoost model is best applied to the prediction of TC intensity at short lead times. At a $6 \mathrm{~h}$ lead time, the MAE and NRMSE values obtained using the XGBoost model were better than those of the LSTM model, for storms of all intensity levels. The LSTM model can sometimes provide better performance than the XGBoost model at longer lead times. At a $24 \mathrm{~h}$ lead time, the LSTM model is better suited for the prediction of tropical storms, severe tropical storms, and super typhoons than is the XGBoost model. However, the XGBoost method and the LSTM method may not fit the prediction of the TC intensity in the South China Sea at $72 \mathrm{~h}$ lead time. This limitation is 
likely attributable to the relatively low number of samples concerning TC events at $72 \mathrm{~h}$ lead time. The lack of sample is one of the bottlenecks for predicting TC intensity using non-linear method [58]. Overall, both models offer improved Fengyun-2 satellite data utilization over that of other models and represent promising advances in TC intensity prediction at $6,12,18$, and $24 \mathrm{~h}$ lead times.

\section{Conclusions}

Using TBB features derived from FY-2 satellite data, best-track data derived from the CMA-STI, and environmental information taken from the ERA-Interim dataset as input data, we used the XGBoost model to simulate and predict the intensity of TCs in the South China Sea, at lead times of 6, 12, 18 , and $24 \mathrm{~h}$. We analyzed the influence of satellite data utilization and explored the most accurate parameter sets under three scenarios. The examined prediction models were built based on climatology and persistence predictors, environmental predictors, and satellite-based predictors. The traditional extraction method for satellite image data directly extracts average values from the images, but it cannot fully reflect the cloud-based characteristics. Based on existing research, this study employed a high-precision and maneuverable ring segmentation method for satellite-based predictor extraction and compared its performance to that of the conventional method. We trained the models using TC event data from 2006-2012 and verified the accuracy of their TC-intensity predictions using TC event data from 2013-2017. The results were as follows.

(1) The Fengyun-2 satellite data can be used to increase the accuracy of TC intensity forecasts for the South China Sea at 6, 12, 18, and $24 \mathrm{~h}$ lead times. We analyzed the influence of satellite data on the accuracy of TC intensity forecasts under three models; the MAEs of models A2 and A3, which employed satellite-based prediction factors, were smaller than the MAE of model A1 at 6, 12, 18, and $24 \mathrm{~h}$ lead times.

(2) The ring segmentation method was found to be a suitable extraction method for satellite data. Compared with that of model A2 (which considered satellite predictors extracted as averages), the MAE of model A3 decreased by $0.47 \%, 1.79 \%, 1.91 \%$, and $5.04 \%$ at $6,12,18$, and $24 \mathrm{~h}$ lead times, respectively. The relative biases of model A3 were $8.62 \%, 12.57 \%, 16.48 \%$, and $19.04 \%$ at $6,12,18$, and $24 \mathrm{~h}$ lead times, respectively; the R squares of model A3 were $0.91,0.82,0.73,0.63$ at $6,12,18$, and $24 \mathrm{~h}$ lead times, respectively; the NRMSEs of model A3 were 5.28, 8.19, 9.42, and 10.51 at 6, 12, 18, and $24 \mathrm{~h}$ lead times, respectively.

(3) The TC intensity forecast results of the LSTM and XGBoost models for the South China Sea from 2013 to 2017 were analyzed. The XGBoost model was found to be more stable and better suited for $6 \mathrm{~h}$ TC intensity predictions than the LSTM model.

Overall, these results suggest that the proposed XGBoost model and extraction method can be used to accurately estimate TC intensities in the South China Sea, using satellite data and optimized parameter sets. The MAE, NRMSE, and CC results used to compare the three different modeling approaches further suggest that satellite data might be the most important type of predictor and that the ring segmentation method might be the best available extraction method for such satellite data.

Author Contributions: Q.J. contributed to the development of the original idea for the study and wrote the majority of the paper. X.F. contributed to the manuscript structure. J.L. contributed to the data analysis. Z.X. analyzed and processed the TC activity. H.J. helped with field work, discussion, and revisions. All authors have read and agreed to the published version of the manuscript.

Funding: This research was supported by the Strategic Priority Research Program of the Chinese Academy of Sciences, grant number XDA19080101, the National Key Research and Development Program of China, grant number 2016YFB0501502 and 2016YFB0501503, and the Key Research Program of the Chinese Academy of Sciences, grant number KFZD-SW-317.

Acknowledgments: All the data used in this study are available as follows: (1) The 2006-2017 South China Sea TC datasets were downloaded from the CMA-STI Best Track Dataset of TCs over the Western North Pacific (http: //www.typhoon.gov.cn/). (2) The environmental datasets were produced by the ECMWF Re-Analysis (ERA-Interim) dataset. This dataset provides assimilation analysis data four times daily at 00:00, 06:00, 12:00, and 18:00, with a spatial resolution of $1^{\circ} \times 1^{\circ}$. (3) The FY-2 data obtained for this study were downloaded from the National Satellite Meteorological Center FengYun Satellite Data Center (http://satellite.nsmc.org.cn/PortalSite/Data/FileShow.aspx). 
The selected satellite product was the TBB, which represents the most primitive observational data for cloud formation and enhancement display. The authors thank the four anonymous reviewers for their valuable comments.

Conflicts of Interest: The authors declare no conflict of interest.

\section{References}

1. Demaria, M.; Sampson, C.R.; Knaff, J.A.; Musgrave, K.D. Is Tropical Cyclone Intensity Guidance Improving? Bull. Am. Meteorol. Soc. 2014, 95, 387-398. [CrossRef]

2. Kovordányi, R.; Roy, C. Cyclone track forecasting based on satellite images using artificial neural networks. ISPRS J. Photogramm. Remote. Sens. 2009, 64, 513-521. [CrossRef]

3. Ichikawa, H.; Masunaga, H.; Tsushima, Y.; Kanzawa, H. Analysis of Cloud Properties Associated with Tropical Convection in Climate Models and Satellite Data. J. Meteorol. Soc. Jpn. 2012, 90, 629-646. [CrossRef]

4. Mueller, K.J.; Demaria, M.; Knaff, J.; Kossin, J.P.; Haar, T.V. Objective Estimation of Tropical Cyclone Wind Structure from Infrared Satellite Data. Weather Forecast. 2006, 21, 990-1005. [CrossRef]

5. Ghosh, T.; Krishnamurti, T.N. Improvements in Hurricane Intensity Forecasts from a Multimodel Superensemble Utilizing a Generalized Neural Network Technique. Weather Forecast. 2018, 33, 873-885. [CrossRef]

6. Roy, C.; Kovordányi, R. Tropical cyclone track forecasting techniques-A review. Atmos. Res. 2012, 104-105, 40-69. [CrossRef]

7. DeMaria, M.; Mainelli, M.; Shay, L.K.; Knaff, J.A.; Kaplan, J. Further improvements to the Statistical Hurricane Intensity Prediction Scheme (SHIPS). Weather Forecast. 2005, 20, 531-543. [CrossRef]

8. Knaff, J.A.; Sampson, C.R.; Demaria, M. An Operational Statistical Typhoon Intensity Prediction Scheme for the Western North Pacific. Weather Forecast. 2005, 20, 688-699. [CrossRef]

9. Gao, S.; Chiu, L.S. Development of Statistical Typhoon Intensity Prediction: Application to Satellite-Observed Surface Evaporation and Rain Rate (STIPER). Weather Forecast. 2012, 27, 240-250. [CrossRef]

10. Chaudhuri, S.; Dutta, D.; Goswami, S.; Middey, A. Intensity forecast of tropical cyclones over North Indian Ocean using multilayer perceptron model: Skill and performance verification. Nat. Hazards 2013, 65, 97-113. [CrossRef]

11. Chaudhuri, S.; Dutta, D.; Goswami, S.; Middey, A. Track and intensity forecast of tropical cyclones over the North Indian Ocean with multilayer feed forward neural nets. Meteorol. Appl. 2015, 22, 563-575. [CrossRef]

12. Huang, Y.; Jin, L. A prediction scheme with genetic neural network and Isomap algorithm for tropical cyclone intensity change over western North Pacific. Theor. Appl. Clim. 2013, 121, 143-152. [CrossRef]

13. Gao, S.; Zhang, W.; Liu, J.; Lin, I.-I.; Chiu, L.S.; Cao, K. Improvements in Typhoon Intensity Change Classification by Incorporating an Ocean Coupling Potential Intensity Index into Decision Trees. Weather Forecast. 2016, 31, 95-106. [CrossRef]

14. Asif, A.; Dawood, M.; Jan, B.; Khurshid, J.; DeMaria, M.; Minhas, F.U.A.A. PHURIE: Hurricane intensity estimation from infrared satellite imagery using machine learning. Neural Comput. Appl. 2018. [CrossRef]

15. Wang, Z. What is the Key Feature of Convection Leading up to Tropical Cyclone Formation? J. Atmos. Sci. 2018, 75, 1609-1629. [CrossRef]

16. Fetanat Fard Haghighi, G. Tropical Cyclone Intensity Estimation Using Temporal and Spatial Features from Satellite Data. Ph.D. Thesis, North Carolina Agricultural and Technical State University, Greensboro, NC, USA, 2013.

17. Zhang, W.; Gao, S.; Chen, B.; Cao, K. The application of decision tree to intensity change classification of tropical cyclones in western North Pacific. Geophys. Res. Lett. 2013, 40, 1883-1887. [CrossRef]

18. Chen, T.; Guestrin, C. XGBoost: A Scalable Tree Boosting System. In Proceedings of the Acm Sigkdd International Conference on Knowledge Discovery \& Data Mining, San Francisco, CA, USA, 13-17 August 2016.

19. Ren, X.D.; Guo, H.N.; Li, S.H.; Wang, S.L.; Li, J.H. A Novel Image Classification Method with CNN-XGBoost Model. In Digital Forensics and Watermarking; Kraetzer, C., Shi, Y.Q., Dittmann, J., Kim, H.J., Eds.; Springer: Berlin/Heidelberg, Germany, 2017; Volume 10431, pp. 378-390. 
20. Chittaragi, N.B.; Koolagudi, S.G. Acoustic Features based Word Level Dialect Classification using SVM and Ensemble Methods. In Proceedings of the 2017 Tenth International Conference on Contemporary Computing, NOIDA, India, 10-12 August 2017; Aluru, S., Kalyanaraman, A., Ucar, B., Kothapalli, K., Halappanavar, M., Madduri, K., Govindaraju, M., Xia, Y., Prasad, S., Barnas, M., et al., Eds.; IEEE: New York, NY, USA, 2017; pp. 178-183.

21. Tahmassebi, A.; Wengert, G.J.; Helbich, T.H.; Bago-Horvath, Z.; Alaei, S.; Bartsch, R.; Dubsky, P.; Balizen, P.; Clausen, P.; Kapetas, P.; et al. Impact of Machine Learning With Multiparametric Magnetic Resonance Imaging of the Breast for Early Prediction of Response to Neoadjuvant Chemotherapy and Survival Outcomes in Breast Cancer Patients. Investig. Radiol. 2019, 54, 110-117. [CrossRef]

22. Jin, Q.; Fan, X.; Liu, J.; Xue, Z.; Jian, H. Using eXtreme Gradient BOOSTing to Predict Changes in Tropical Cyclone Intensity over the Western North Pacific. Atmosphere 2019, 10, 341. [CrossRef]

23. Yang, R.; Tang, J.; Sun, D. Association Rule Data Mining Applications for Atlantic Tropical Cyclone Intensity Changes. Weather Forecast. 2011, 26, 337-353. [CrossRef]

24. Yang, R.; Tang, J.; Kafatos, M. Improved associated conditions in rapid intensifications of tropical cyclones. Geophys. Res. Lett. 2007, 34. [CrossRef]

25. Ming, Y.; Wei, Z.; Hui, Y.; Lu, X.; Feng, J.; Fan, Y.; Zhu, Y.; Chen, D. An Overview of the China Meteorological Administration Tropical Cyclone Database. J. Atmospheric Ocean. Technol. 2014, 31, 287-301.

26. Kalnay, E.; Kanamitsu, M.; Kistler, R.; Collins, W.; Deaven, D.; Gandin, L.; Iredell, M.; Saha, S.; White, G.; Woollen, J.; et al. The NCEP/NCAR 40-year reanalysis project. Bull. Am. Meteorol. Soc. 1996, 77, 437-472. [CrossRef]

27. Huang, X.; Guan, Z.; He, L.; Huang, Y.; Zhao, H. A PNN prediction scheme for local tropical cyclone intensity over the South China Sea. Nat. Hazards 2016, 81, 1249-1267. [CrossRef]

28. Longsheng, L.; Xinyan, L.; Shuanzhu, G. Overview of typhoon activities over western North Pacific and the South China Sea. J. Mar. Meteorol. 2019, 39, 1-12.

29. Loy, K.C.; Sinha, P.C.; Liew, J.; Tangang, F.; Husain, M.L. Modeling storm surges associated with super typhoon durian in South China Sea. Nat. Hazards 2014, 70, 23-37. [CrossRef]

30. Berrisford, P.; Dee, D.P.; Poli, P.; Brugge, R.; Mark, F.; Manuel, F.; Kållberg, P.W.; Kobayashi, S.; Uppala, S.; Adrian, S. The ERA-Interim Archive Version 2.0; ECMWF: Shinfield Park, Reading, UK, 2011.

31. Zhu, P.J.; Zheng, Y.G.; Zheng, P.Q. Asymmetric Distribution of Convection Associated with Tropical Cyclones Making Landfall on the East China Coast. J. Trop. Meteorol. 2012, 18, 436-444.

32. Wang, X.; Guo, Q.; Wen, R. Inner dynamic mechanism analysis for tropical cyclone rapid intensification based on FY-2 cloud motion. J. Infrared Millim. Waves 2018, 37, 790-798. [CrossRef]

33. Zhou, Y.S.; Wu, T.Y. Composite analysis of precipitation intensity and distribution characteristics of western track landfall typhoons over China under strong and weak monsoon conditions. Atmos. Res. 2019, 225, 131-143. [CrossRef]

34. FENGYUN Satellite Data Center. Available online: http://satellite.nsmc.org.cn/PortalSite/Data/Satellite.aspx (accessed on 24 June 2019).

35. Aoki, T. A Statistical Prediction of the Tropical Cyclone Position Based on Persistence Climatological Factor in the Western North Pacific (the PC method). Geophs. Mag. 1979, 38, 17-27.

36. Baik, J.J.; Paek, J.S. A neural network model for predicting typhoon intensity. J. Meteorol. Soc. Jpn. 2000, 78, 857-869. [CrossRef]

37. Dongqing, Z. Research on Tropical Cyclone in the South China Sea Forecast; Nanjing Normal University: Nanjing, China, 2012.

38. Kalnay, E. Atmospheric Modeling, Data Assimilation and Predictability; Cambridge University Press: Cambridge, UK, 2003.

39. Demaria, M.; Kaplan, J. Sea Surface Temperature and the Maximum Intensity of Atlantic Tropical Cyclones. J. Climate 1994, 7, 1324-1334. [CrossRef]

40. Holland, G.J. The Maximum Potential Intensity of Tropical Cyclones. J. Atmos. Sci. 1997, 54, $2519-2541$. [CrossRef]

41. Miller, B.I. O the Maximum Intensity of Hurricanes. J. Atmos. Sci. 1958, 15, 184-195. [CrossRef]

42. Merrill, R.T. An experiment in the statistical prediction of tropical cyclone intensity change. In Proceedings of the 17th Conference on Hurricanes and Tropical Meteorology, Miami, FL, USA, 7-10 April 1987. 
43. Wikle, C.K. Atmospheric Modeling, Data Assimilation, and Predictability. Technometrics 2002, 47, 521. [CrossRef]

44. Geng, H.; Sun, J.; Wei, Z.; Chao, H. Study on Index Model of Tropical Cyclone Intensity Change Based on Projection Pursuit and Evolution Strategy. In Proceedings of the 2015 IEEE Symposium Series on Computational Intelligence (SSCI), Cape Town, South Africa, 7-10 December 2015.

45. Chen, P.Y.; Duan, Y.H.; Yu, H.; Hu, C.M. Application of equivalent black body temperature in the forecast of tropical cyclone intensity. Acta Meteorol. Sin. 2007, 21, 465-475.

46. Steranka, J.; Rodgers, E.B.; Gentry, R.C. The Relationship between Satellite Measured Convective Bursts and Tropical Cyclone Intensification. Mon. Weather. Rev. 1986, 114, 1539. [CrossRef]

47. Fitzpatrick, P.J. Understanding and forecasting tropical cyclone intensity change with the Typhoon Intensity Prediction Scheme (TIPS). Weather Forecast. 1997, 12, 826-846. [CrossRef]

48. Weatherford, C.L.; Gray, W.M. Typhoon Structure as Revealed by Aircraft Reconnaissance. Part I: Data Analysis and Climatology. Mon. Weather Rev. 1988, 116, 1032-1043. [CrossRef]

49. Mundell, D.B. Prediction of Tropical Cyclone Rapid Intensification Intensification; Colorado State University: Fort Collins, CO, USA, 1990.

50. Olander, T.L.; Velden, C.S. The Advanced Dvorak Technique: Continued Development of an Objective Scheme to Estimate Tropical Cyclone Intensity Using Geostationary Infrared Satellite Imagery. Weather Forecast. 2007, 22, 287-298. [CrossRef]

51. Hochreiter, S.; Schmidhuber, J. Long Short-Term Memory. Neural Comput. 1997, 9, 1735-1780. [CrossRef]

52. Gao, S.; Zhao, P.; Pan, B.; Yaru, L.I.; Zhou, M.; Jiangling, X.U.; Zhong, S.; Shi, Z. A nowcasting model for the prediction of typhoon tracks based on a long short term memory neural network. Acta Oceanol. Sin. 2018, 37, 8-12. [CrossRef]

53. Ma, X.L.; Tao, Z.M.; Wang, Y.H.; Yu, H.Y.; Wang, Y.P. Long short-term memory neural network for traffic speed prediction using remote microwave sensor data. Transp. Res. Pt. C-Emerg. Technol. 2015, 54, 187-197. [CrossRef]

54. Kong, Y.L.; Huang, Q.; Wang, C.; Chen, J.; Chen, J.; He, D. Long Short-Term Memory Neural Networks for Online Disturbance Detection in Satellite Image Time Series. Remote Sens. 2018, 10, 452. [CrossRef]

55. Muramatsu, T. Diurnal Variations of Satellite-Measured TBB Areal Distribution and Eye Diameter of Mature Typhoons. J. Meteorol. Soc. Jpn. 2007, 61, 77-90. [CrossRef]

56. DeMaria, M.; Zehr, R.M.; Kossin, J.P.; Knaff, J.A. The use of GOES imagery in statistical hurricane intensity prediction. In Proceedings of the 25th Conference on Hurricanes and Tropical Meteorology, San Diego, CA, USA, 29 April-3 May 2002; pp. 120-121.

57. Ruan, Z.X.; Wu, Q.Y. Precipitation, Convective Clouds, and Their Connections with Tropical Cyclone Intensity and Intensity Change. Geophys. Res. Lett. 2018, 45, 1098-1105. [CrossRef]

58. Pradhan, R.; Aygun, R.; Maskey, M.; Ramachandran, R.; Cecil, D. Tropical Cyclone Intensity Estimation Using a Deep Convolutional Neural Network. IEEE Trans. Image Process. 2018, 27, 692-702. [CrossRef]

(C) 2020 by the authors. Licensee MDPI, Basel, Switzerland. This article is an open access article distributed under the terms and conditions of the Creative Commons Attribution (CC BY) license (http://creativecommons.org/licenses/by/4.0/). 